University of New Orleans

ScholarWorks@UNO

2003

\title{
MIM and nonlinear least-squares inversions of AEM data in Barataria basin, Louisiana
}

Melissa Whitten Bryan

University of New Orleans

Kenneth W. Holladay

University of New Orleans

Clyde J. Bergeron Jr.

University of New Orleans

Juliette W. Ioup

University of New Orleans

George E. loup

University of New Orleans

Follow this and additional works at: https://scholarworks.uno.edu/phys_facpubs

Part of the Physics Commons

\section{Recommended Citation}

Geophysics 68, 1126 (2003)

This Article is brought to you for free and open access by the Department of Physics at ScholarWorks@UNO. It has been accepted for inclusion in Physics Faculty Publications by an authorized administrator of ScholarWorks@UNO.

For more information, please contact scholarworks@uno.edu. 


\title{
Case History
}

\section{MIM and nonlinear least-squares inversions of AEM data in Barataria basin, Louisiana}

\author{
Melissa Whitten Bryan*, Kenneth W. Holladay $\ddagger$, Clyde J. Bergeron, Jr.*, Juliette W. loup*, \\ and George E. loup*
}

\begin{abstract}
An airborne electromagnetic survey was performed over the marsh and estuarine waters of the Barataria basin of Louisiana. Two inversion methods were applied to the measured data to calculate layer thicknesses and conductivities: the modified image method (MIM) and a nonlinear least-squares method of inversion using two two-layer forward models and one three-layer forward model, with results generally in good agreement. Uniform horizontal water layers in the near-shore Gulf of Mexico with the fresher (less saline, less conductive) water above the saltier (more saline, more conductive) water can be seen clearly. More complex near-surface layering showing decreasing salinity/conductivity with
\end{abstract}

depth can be seen in the marshes and inland areas. The first-layer water depth is calculated to be $1-2 \mathrm{~m}$, with the second-layer water depth around $4 \mathrm{~m}$. The first-layer marsh and beach depths are computed to be $0-3 \mathrm{~m}$, and the second-layer marsh and beach depths vary from 2 to $9 \mathrm{~m}$. The first-layer water conductivity is calculated to be 2-3 S/m, with the second-layer water conductivity around 3 to $4 \mathrm{~S} / \mathrm{m}$ and the third-layer water conductivity $4-5 \mathrm{~S} / \mathrm{m}$. The first-layer marsh conductivity is computed to be mainly $1-2 \mathrm{~S} / \mathrm{m}$, and the second- and third-layer marsh conductivities vary from 0.5 to $1.5 \mathrm{~S} / \mathrm{m}$, with the conductivities decreasing as depth increases except on the beach, where layer three has a much higher conductivity, ranging up to $3 \mathrm{~S} / \mathrm{m}$.

\section{INTRODUCTION}

A frequency-domain airborne active electromagnetic (AEM) system determines ground and water conductivity by generating low-frequency electromagnetic fields and measuring the induced secondary field whose strength is a function of the conductivity of the surface below the sensor (Fountain, 1998). The measured fields are a volume average over the lateral footprint of the sensor (which depends on the instrument height) and the depth of penetration of the field (Xie et al., 1998). The penetration of the field depends on the conductivity of the ground or water and the frequency of the field (Kovacs et al., 1995). Various schemes have been implemented for inverting frequency-domain AEM fields to obtain layer thickness and conductivities (see, for example, Anderson, 1979; Sengpiel, 1983; Bergeron, 1986; Won and Smits, 1987; Pelletier and Holladay, 1994; Huang and Fraser, 1996; Ellis, 1998).
Good agreement has been found between modified image method (MIM) inversion results in the Gulf of Mexico with conductivity/temperature/depth (CTD) casts along flight lines and ground-based measurements in this area (Bergeron et al., 1998, 1999, 2001). This demonstrates the validity of the MIM inversion technique and the stability of the AEM measurement system. Results from a nonlinear least-squares method have previously been verified in other areas with depths obtained from NOAA bathymetric charts (Pelletier and Holladay, 1994).

To compare inversions over both water and land, an AEM survey over the marsh and estuarine waters of the Barataria basin of Louisiana was conducted in 1995. Inversions for layer thicknesses and conductivities using MIM and a nonlinear least-squares method are performed and described in this paper. Two different forward models for the nonlinear leastsquares inversions are used. The outline of the paper is as follows: Survey data acquisition and general data processing are

Manuscript received by the Editor November 14, 2001; revised manuscript received February 3, 2003.

*University of New Orleans, Department of Physics, New Orleans, Louisiana 70148. E-mail: jioup@uno.edu.

$\ddagger$ University of New Orleans, Department of Mathematics, New Orleans, Louisiana 70148.

(C) 2003 Society of Exploration Geophysicists. All rights reserved. 
discussed, followed by a description of the field data corrections applied before inversion. Next are sections outlining the MIM and least-squares inversion techniques used to compute the layer thicknesses and conductivities. Results are then presented and conclusions drawn.

\section{DATA ACQUISITION}

The AEM field data used in this analysis are part of the results of a survey of Barataria Bay, Louisiana, collected in June 1995. The survey was conducted by U.S. Navy personnel based at Stennis Space Center, Mississippi, using a Naval Research Laboratory AEM system (Pelletier and Wu, 1989; Mozley et al., 1991; Pelletier and Holladay, 1994; Bergeron et al., 1998, 1999, 2001). This survey was performed over the marsh and estuarine waters of the Barataria basin as a part of an integrated study of the hydrology and carbon cycle of the basin. A global positioning system was used to geoposition the data. Latitudes and longitudes were recorded in degrees to six decimal places. The bird was flown at an approximate altitude of $18 \mathrm{~m}$ above the surface. The radar altimeter on the bird failed, and the system altitude was determined from the highest frequency AEM field measurements. Of the more than $350 \mathrm{~km}$ of data points taken, the data discussed in this paper comprise approximately $45 \mathrm{~km}$ taken from flight lines 2 and 6 . Figure 1 shows the survey area with these flight lines overlaid.

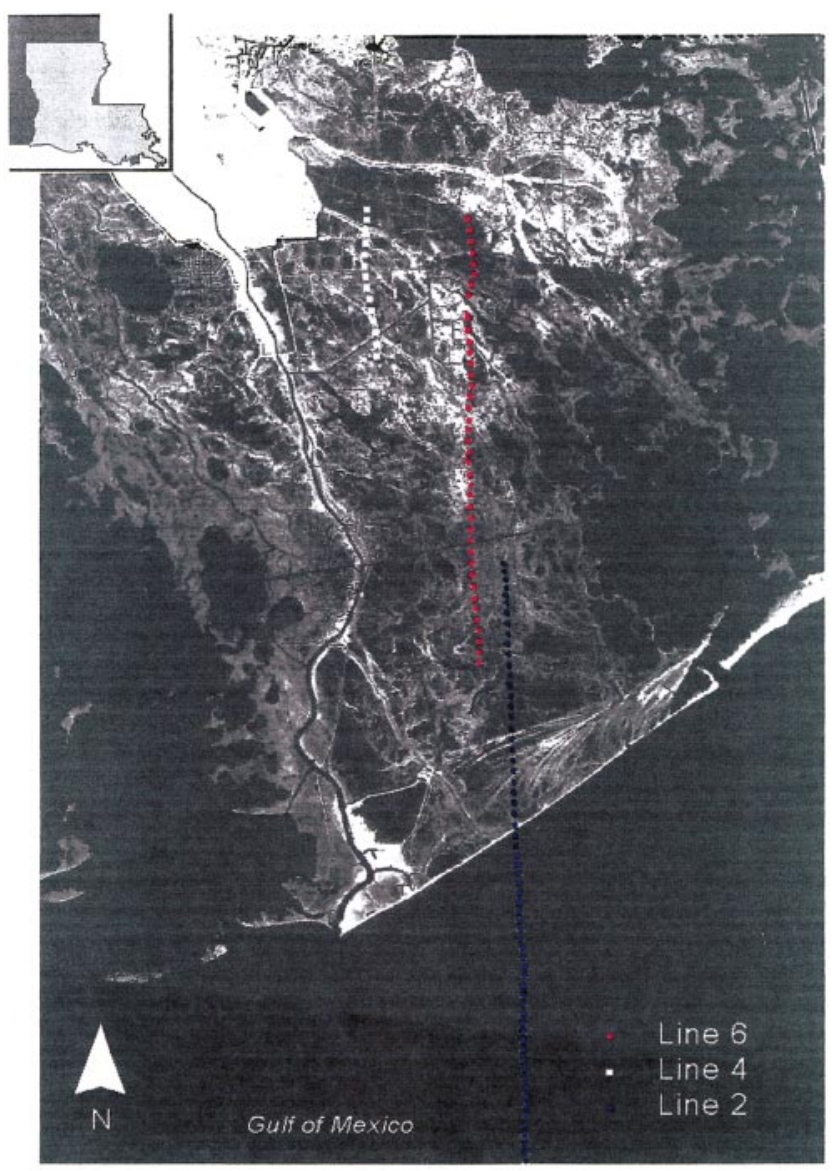

FIG. 1. Barataria basin, Louisiana, survey area with flight lines 2, 4, and 6 marked. Flight line 2 (blue) is to the south over the Gulf of Mexico, beach, and marsh. Flight line 6 (red) is to the north over marsh and land.
The AEM system primary waveform was digitally constructed from the cosine functions of six frequencies: 29970 , 11670, 4530, 1770, 690, and $270 \mathrm{~Hz}$ (Pelletier and Wu, 1989; Mozley et al., 1991; Pelletier and Holladay, 1994; Bergeron et al., 1998, 1999, 2001). The amplitude and phase of the secondary fields at these frequencies were determined by digitally convolving the measured secondary field with the original cosine functions. The fields were sampled 30 times per second and averaged to produce one data point per second.

Water temperature and conductivity samples were taken just prior to the AEM flights at depths along the part of flight line 2 that was over the Gulf of Mexico. Those samples were used to calibrate the AEM fields in the lateral footprint of these points (Bergeron et al., 1998, 1999, 2001).

\section{DATA PROCESSING}

The total field resulting from an AEM source near a conducting medium can be modeled as a primary dipole field plus a secondary field generated by induced currents in the conducting medium. Sommerfeld provided the first formal solution for this problem (Sommerfeld, 1909). The resultant secondary field is complex, with both in-phase and quadrature components, and is given in terms of integral expressions developed by Sommerfeld (Frischknecht, 1967). The integral has the form of a Hankel transform, an integral transform whose kernel is a zeroth-order Bessel function.

The processing for this paper is based on two- and three-layer models. The model parameters are defined as the altitude of the transmitter/receiver coils $h$, the layer depth $d_{i}$, and the layer conductivity $\sigma_{i}$, where the subscript denotes the layer number.

\section{FIELD DATA CORRECTIONS}

Drift corrections to the raw data are made by a linear interpolation procedure (Bergeron et al., 2001). High-altitude secondary field data (which should be zero) recorded at the beginnings and ends of the flight lines provide the endpoints for the linear drift correction functions.

The secondary field varies inversely with the cube of the altitude. Therefore, variations in the secondary field caused by vertical excursions of the AEM system can hide changes in the field associated with changes in the conductivity along the flight path. Hence, a continuation procedure is applied to the field data to remove the altitude-induced variation in the secondary field (Bergeron et al., 1989b, 1998, 1999).

\section{MIM INVERSION}

The modified image method is an algebraic representation of the secondary field computed from the measured fields (Bergeron, 1986; Bergeron et al., 1989a, b, 2001); therefore, it is a computationally fast, efficient method of calculating layer thicknesses and conductivities. In the MIM representation the source of the secondary field is an approximate image of the primary dipole located at a complex depth below the earth's surface.

The main computational quantity of MIM is $R$, which is the total complex distance between the primary dipole and the secondary dipole in the conductor, scaled in units of the transmitter/receiver coil spacing $\rho$. The altitude of the bird is $h$, the complex effective skin depth is $\delta_{e f f}$, and the first-layer skin depth is $\delta_{1} ; \delta_{\text {eff }}$ and $\delta_{1}$ are obtained from $R$ (Bergeron 
et al., 1998,2001). The computed value of $R$ is given in terms of the measured field. For a horizontal coplanar transmitter and receiver coil configuration, $R$ is related to the ratio $Z$ of the secondary and primary fields (Bergeron et al., 1989a, 2001) as

$$
R=\frac{2 Z^{2}-1}{\left(Z^{2}+1\right)^{5 / 2}},
$$

where $R$ is a function of frequency. Wait's multilayer correction factor $Q$ (Wait, 1951, 1991; Bergeron et al., 2001) is calculated from $R$, i.e., $Q_{\text {exp }}$ is computed from the experimental data:

$$
Q_{\text {exp }}(f)=\frac{\rho R(f)-2 h}{(1-i) \delta_{1}(f)} .
$$

Initially, $R\left(f_{1}\right)$ is computed from the fields at $f_{1}$, the highest system frequency, and $Q_{\text {exp }}\left(f_{1}\right)$ is assumed equal to 1 . Then $h$ and $\delta_{1}$ are determined from the highest frequency data using equation (2) (Bergeron et al., 2001). The conductivity $\sigma_{1}$ of the first layer is computed from $\delta_{1}$. Thicknesses and conductivities for lower layers are obtained sequentially using fields at decreasing frequencies. For the second-highest frequency the first-layer skin depth is assumed modified by the penetration of the fields into the second layer and corrections to first-layer values obtained by iteration. The procedure is outlined and general multilayer equations for depth and conductivity are given by Bergeron et al. (2001).

\section{LEAST-SQUARES INVERSION}

Nonlinear least-squares inversion methods use estimated values for model parameters and a forward model to predict the response to a signal transmitted by the source; they then compare this response to the actual measured data. The discrepancies between the predicted and the measured data are used to improve the parameter estimates. The procedure is iterated to further improve the estimates (Moré, 1978; Fletcher, 1987; Press et al., 1989; Visual Numerics, 1994; Nocedal and Wright, 1999).

A two-layer, i.e., one layer and a half-space, forward algorithm has been used by Pelletier and Holladay (1994) for nonlinear least-squares inversion of data from the Cape Lookout area at the southern end of North Carolina's Outer Banks to obtain relatively good agreement with ground truth. The twolayer forward model (W-S model) is based on an algorithm described by Won and Smits (1987).

A multiple-layer forward algorithm coded as the EMLOOPS program (Anderson, 1979) was obtained from the USGS, modified, and used to compute frequency-domain responses for a horizontal coplanar loop-loop orientation. It is based on evaluating the Sommerfeld integrals (Sommerfeld, 1909; Wait, 1951, 1991). The subroutine can include up to ten layers. Both the two-layer W-S model and the multiple-layer EMLOOPS-based model are used to invert the data discussed here.

Different combinations of frequencies provide different information about the test area being studied. For least-squares methods using a two-layer forward algorithm, at least three frequencies must be used to determine the least-squares residuals. For the multiple-layer algorithms, there must be at least one more frequency than the number of model layers to determine the residuals. However, in both the W-S and EMLOOPS models, more than the minimum required number of frequencies can be used with the least-squares programs. The minimum residuals will never be zero because of the noise of the AEM measuring system and because of model misfit. Model misfit occurs when a layered model uses an inadequate number of layers to describe the physical system or the physical system is simply not well modeled using layers.

\section{RESULTS}

The AEM data are inverted using MIM and least squares to produce layer depths and conductivities along two representative flight lines from the Barataria basin survey. For the leastsquares two- and three-layer models, using the MIM output values as the initial guess parameters at each point produces the results shown in Figures 2-5 below. Other initial values require more least-squares iterations (more computer time) but eventually converge to the same results.

Figure 2 shows results of inversions along flight line 2 using two-layer models, i.e., one layer and a half-space. The southernmost part of flight line 2 between approximately $28.98^{\circ}$ and $29.12^{\circ}$ latitude lies over the Gulf of Mexico. The northernmost part of flight line 2 above approximately $29.12^{\circ}$ latitude is over beach and land. Figure 2a shows the first-layer thickness versus

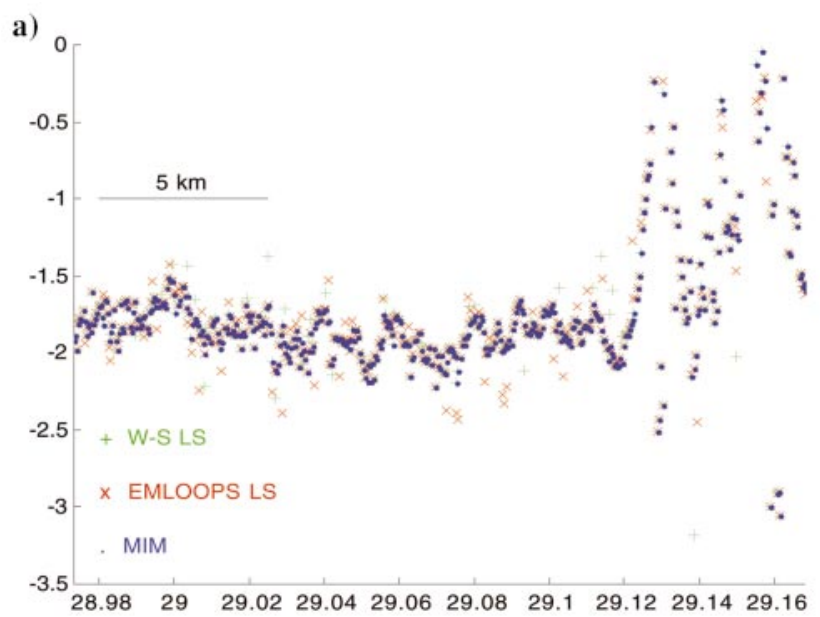

b)

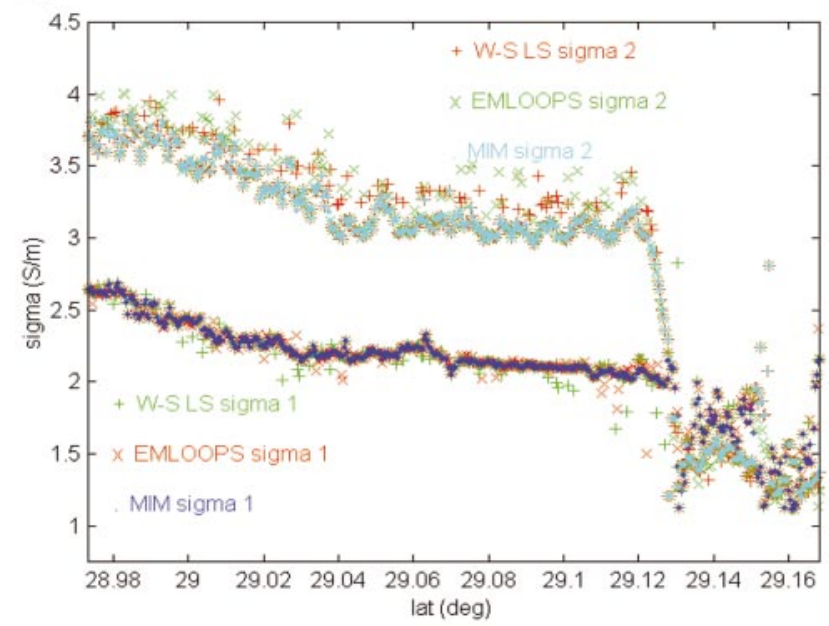

FIG. 2. Flight line 2 two-layer models for MIM compared to both least-squares two-layer models. (a) Depth vs. latitude. (b) Conductivity vs. latitude. 
latitude. Figure $2 \mathrm{~b}$ shows $\sigma_{1}$, the conductivity of the first layer, and $\sigma_{2}$, the conductivity of the half-space, versus latitude. The MIM and both of the nonlinear least-squares two-layer models are in very good agreement for the layer depth over water. If the first-layer parameters are approximately correct in a two-layer model, the second-layer conductivity can be attributed to the conductivity of the lower half-space (Pelletier and Holladay, 1994; Bergeron et al., 1989a, 1998, 1999). In areas where the water depth is at least $1.5 \mathrm{~m}$, both nonlinear least-squares twolayer models agree well with the MIM results for the first-layer conductivity, as shown in Figure 2b. In the same region, the second-layer conductivities from both nonlinear least-squares two-layer models show fairly good agreement with MIM, although slightly larger in value.

The relative flatness and continuity to the left in Figure 2a indicates the relatively flat layering of the Gulf of Mexico water in comparison to the more scattered values, indicating variable layering on the shore, to the right in the figure. Figure $2 \mathrm{~b}$ shows that the conductivity of the second layer of the Gulf water is higher than that of the first layer. This is expected since the first layer is less saline (lower conductivity) water floating on top of heavier, more saline, deeper Gulf water (Wiseman and Garvine, 1995; Bianchi et al., 1999; Rabalais and Turner, 2001). Conductivities of the beach and shore (to the right of Figure 2b) are lower and do not show obvious layering because the earth material is more mixed.

The least-squares W-S two-layer model was run using various combinations of frequencies to determine the effect of frequency. The shapes of the plots remain relatively constant and are in good agreement with the MIM two-layer model that uses the top two frequencies.

Figure 3 shows depths and conductivities versus latitude from inversions using MIM and least-squares EMLOOPS three-layer models along flight line 2. The MIM three-layer model first- and second-layer depths agree well with the corresponding nonlinear least-squares EMLOOPS three-layer model depths, as shown in Figure 3a. The first-layer conductivity $\sigma_{1}$ and second-layer conductivity $\sigma_{2}$ from the MIM threelayer program are in very good agreement with those values from the EMLOOPS three-layer models, as shown in Figure $3 \mathrm{~b}$. However, values for the third-layer conductivity obtained by the least-squares EMLOOPS three-layer model are more scattered than those obtained using the MIM three-layer program. This noisy effect is attributed to model misfit that appears as noise in the least-squares algorithms.

Figure 3a also shows the layering of the Gulf water to the left with less continuous layers on shore to the right. Figure $3 \mathrm{~b}$ shows that the conductivity of each lower layer is larger than the previous layer because of the increasing salinity of the Gulf waters with depth (Wiseman and Garvine, 1995; Bianchi et al., 1999; Rabalais and Turner, 2001).

The least-squares EMLOOPS three-layer model is also run using various combinations of frequencies. Values for second- and third-layer conductivity using the least-squares EMLOOPS three-layer model with four frequencies are increasingly scattered as the number of frequencies used increases from four to six. Scatter increases with layer depth.

Figures 4 and 5 present layer depths and conductivities versus latitude for flight line 6, which is over marsh and land to the north of flight line 2 (see Figure 1). Figure 4 shows two-layer model results, and Figure 5 presents three-layer results. For data taken over areas where the water is less than $2 \mathrm{~m}$ deep, or over marsh or land, the inversion results for both MIM and nonlinear least-squares models are more variable. The inversion results have agreement that varies from very good to significant disagreement. Values from both least-squares models are consistently more scattered than those obtained with MIM, probably from the effects of noise sensitivity.

Data taken along flight line 6 indicate the sensitivity of MIM and least-squares models to the homogeneity of sediment below the flight line. In Figure 1, a canal cuts the flight line at $29.297^{\circ}$ latitude. South of the canal (between approximately $29.204^{\circ}$ and $29.297^{\circ}$ latitude), the region is marshy. Layering is more likely, with sediment below water (Bianchi et al., 1999). North of the canal, at latitudes greater than $29.297^{\circ}$, the surface becomes a region with more solid land areas mixed with areas of water (Bianchi et al., 1999). Uniform horizontal layers are less likely, especially near the surface. In Figures 4 and 5 for latitudes greater than $29.297^{\circ}$, values for first-layer depth and conductivity are more variable than those to the south As shown in Figures $4 b$ and 5b, MIM second- and third-layer conductivities show more continuity than those obtained using
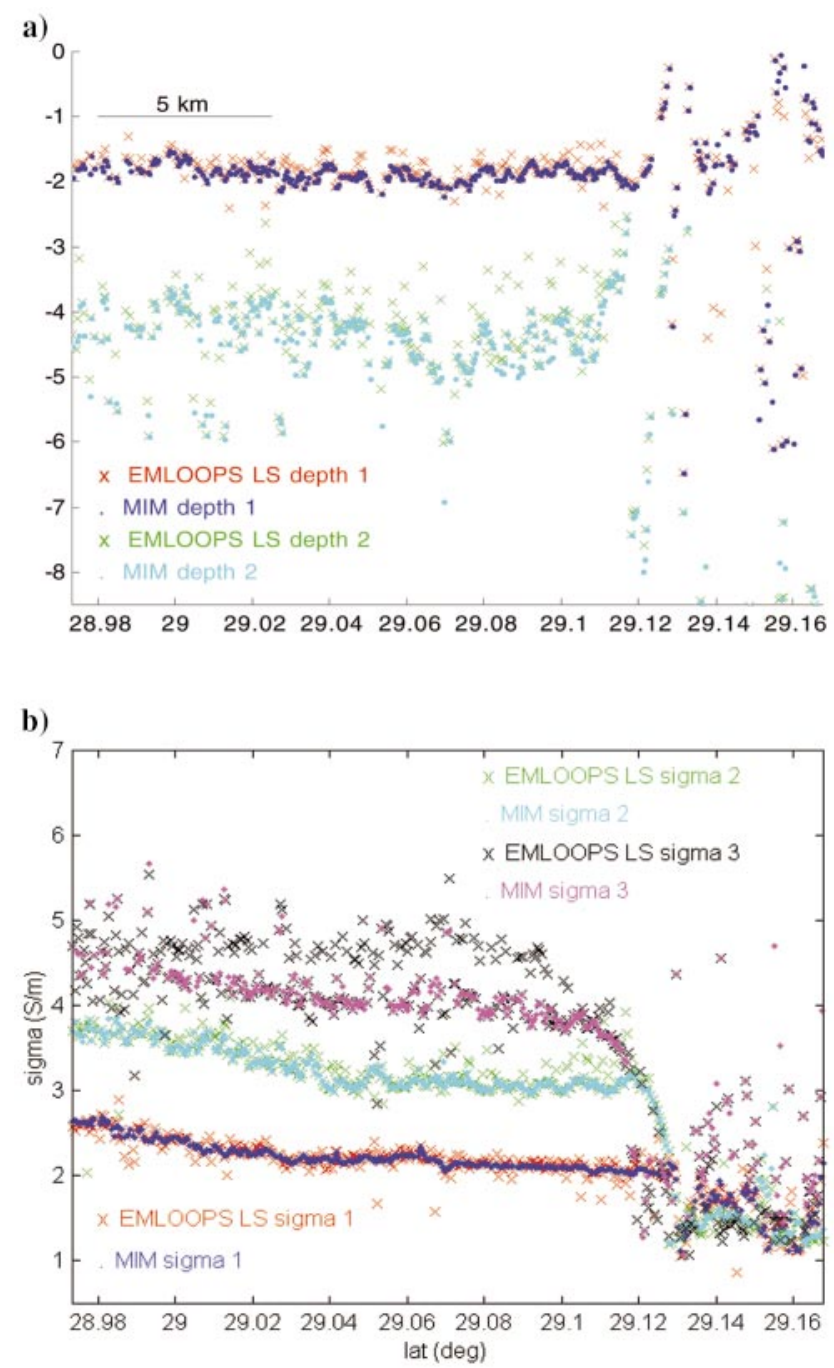

FIG. 3. Flight line 2 three-layer models for MIM compared to the EMLOOPS least-squares three-layer model. (a) Depth vs. latitude. (b) Conductivity vs. latitude. 
the least-squares method. Conductivities (salinities) decrease with depth over the marsh and land, in contrast to the conductivity (salinity) increase with depth of the Gulf of Mexico water.

\section{CONCLUSIONS}

This study demonstrates the good agreement of MIM inversion with nonlinear least-squares methods for both two- and three-layer models. The computing time for 477 sets of data points using the MIM two-layer model is $2.09 \mathrm{~s}$, while that for the least-squares W-S two-layer model is $4.78 \mathrm{~s}$. The leastsquares EMLOOPS two-layer model has a computing time of $28.57 \mathrm{~s}$ for the same number of points. Very little improvement in the inversion is obtained by using least squares after MIM.

The computing times using the least-squares W-S twolayer model (11.32 s) and the least-squares EMLOOPS model $(59.86 \mathrm{~s})$ are large when a bad initial guess is given for the model parameters, i.e., when the MIM output values are not used as the initial forward model values. The least-squares models have two significant sources of error: noise sensitivity and model misfit.
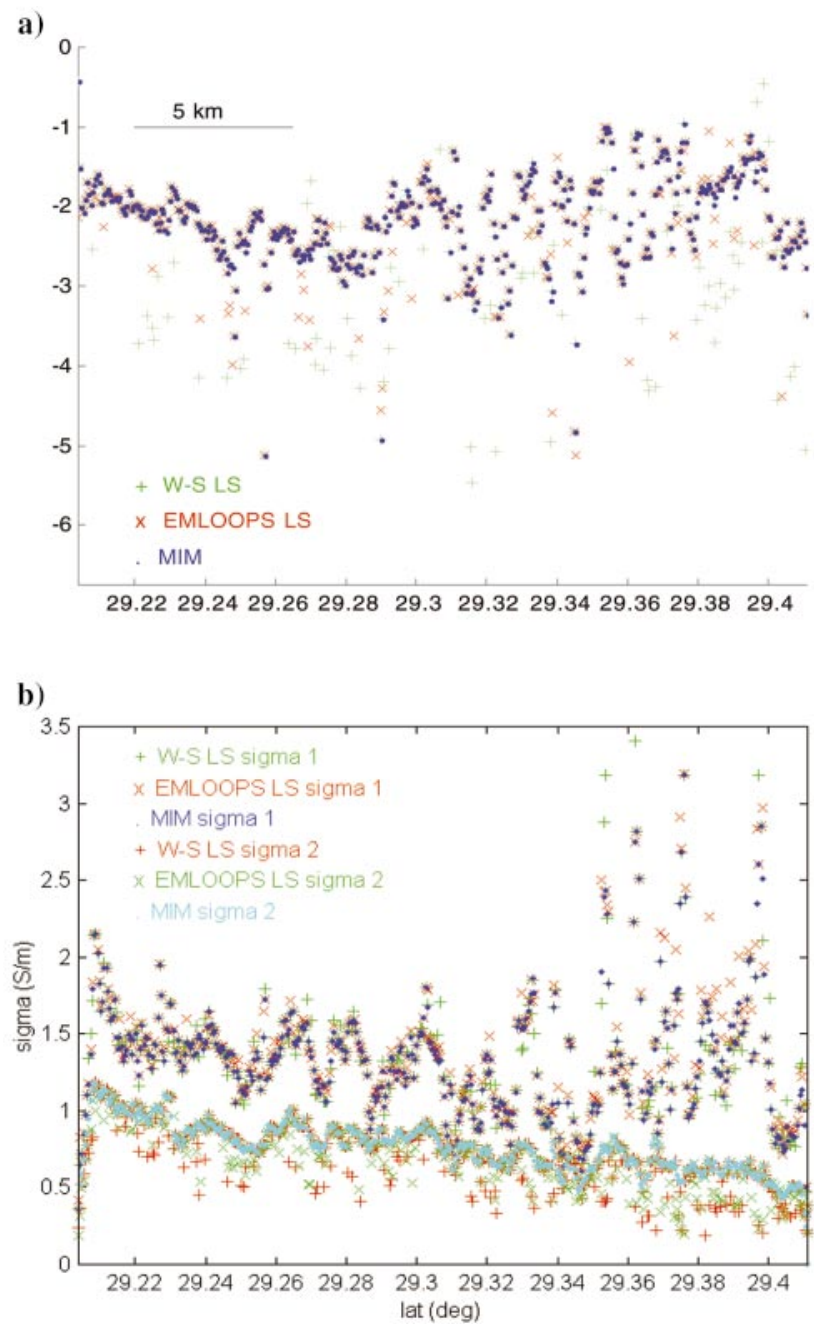

FIG. 4. Flight line 6 two-layer models for MIM compared to both least-squares two-layer models. (a) Depth vs. latitude. (b) Conductivity vs. latitude.
Both MIM and least-squares methods can be useful for inversion of AEM data to obtain layer depths and conductivities in estuarine and marshy environments. In the near-shore Gulf of Mexico, the water near the surface is in the form of uniform horizontal fresh layers, less saline and less conductive than the deeper water. The first layer water depth is about $1-2 \mathrm{~m}$ with a conductivity calculated to be $2-3 \mathrm{~S} / \mathrm{m}$. The second layer water depth is about $4 \mathrm{~m}$ with conductivity $3-4 \mathrm{~S} / \mathrm{m}$. The third layer water conductivity is $4-5 \mathrm{~S} / \mathrm{m}$. In the marshes and inland areas, more complex near-surface layering is observed which shows decreasing salinity/conductivity with depth. The first layer marsh and beach depths are computed to be $0-3 \mathrm{~m}$ with conductivity computed to be mainly $1-2 \mathrm{~S} / \mathrm{m}$. The second layer marsh and beach depths range from 2 to $9 \mathrm{~m}$. The second and third layer marsh conductivities range from 0.5 to $1.5 \mathrm{~S} / \mathrm{m}$, with the conductivities decreasing as depth increases. The beach third layer has a much higher conductivity, ranging up to $3 \mathrm{~S} / \mathrm{m}$.

\section{ACKNOWLEDGMENTS}

The authors wish to acknowledge the support of a grant funded by NASA/EPSCoR and the Louisiana Board of

a)

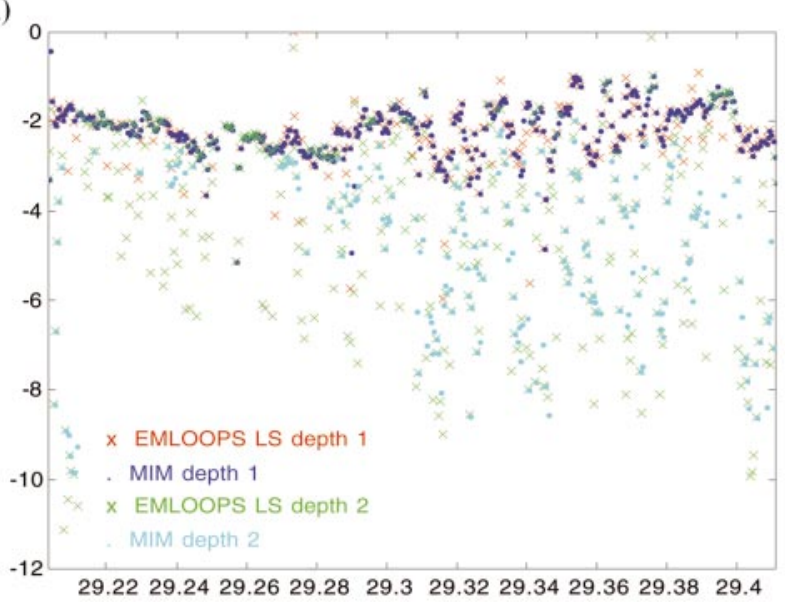

b)

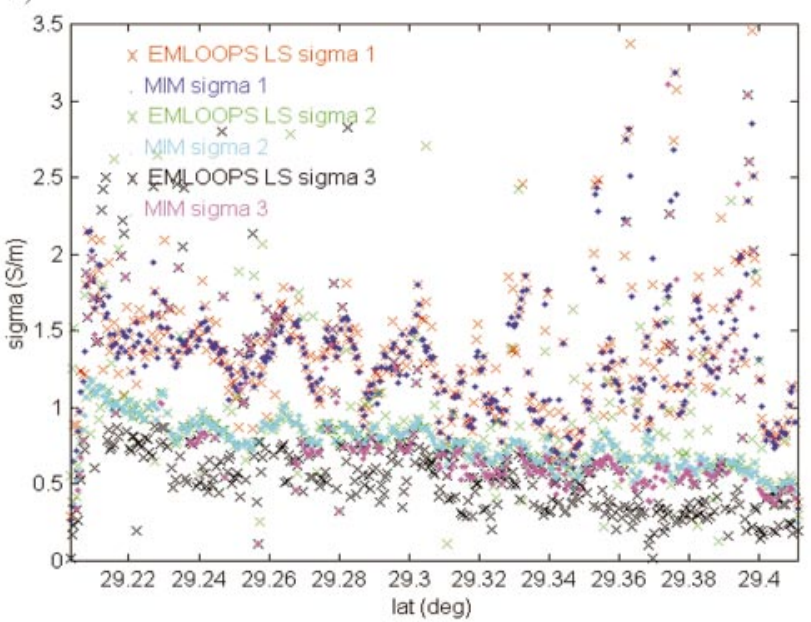

FIG. 5. Flight line 6 three-layer models for MIM compared to the EMLOOPS least-squares three-layer model. (a) Depth vs. latitude. (b) Conductivity vs. latitude. 
Regents. The data collection was jointly funded by this grant and the U.S. Navy, and the AEM flight and data recovery were conducted by the Navy. Alan R. Grissom, Data Systems and Solutions, Huntsville, Alabama, and Lebee S. Grissom Meehan, United Space Alliance, Houston, Texas, provided programming suggestions. David Fitterman, USGS, provided insight into the EMLOOPS forward model program. Denise Reed, UNO, gave references on Gulf of Mexico salinity layers. This paper is part of the dissertation M.W.B. submitted as partial fulfillment of the requirements for the Ph.D. degree.

\section{REFERENCES}

Anderson, W. L., 1979, Program MARQLOOPS: Marquardt inversion of loop-loop frequency sounding: U.S. Geol. Survey Open-File Report 790240

Bergeron, C. J., Jr., 1986, Modified image method: Application to the response of layered ohmic conductors to active electromagnetic sources: J. Appl. Phys, 59, 3901-3908.

Bergeron, C. J., Jr., Brusstar, J., Yi, N., Wu, Y., and Ioup, J. W., 1999, A new vertical continuation procedure for airborne electromagnetic field data from the modified image method: Geophysics, $\mathbf{6 4}, 1364$ 1368.

Bergeron, C. J. Jr., Ioup, J. W., and Michel, G. A., II, 1989a, Interpretation of airborne electromagnetic data using the modified image method: Geophysics, 54, 1023-1030.

Bergeron, C. J., Jr., Ioup, J. W., Wu, Y., Ioup, G. E., and Holladay, K. E., 2001, Multilayer MIM inversion of AEM data: Theory and field example: Geophysics, 66, 125-136.

Bergeron, C. J. Jr. Ioup, J. W. Wu, Y. Ioup, G. E. Holladay, K. W., Hudnall, W. H., Dharmasri, L. C. and Pelletier, R. E., 1998, Correlation of inversion results of AEM data with ground measurements in Barataria Bay, Louisiana: Internat. Conf. on Airborne Electromagnetics, Proceedings, 2.p2, 1-16

Bergeron, C. J., Jr., Morris, T. L., and Ioup, J. W., 1989b, Upward and downward continuation of airborne electromagnetic data: 60th Ann. Internat. Mtg. Soc. Expl. Geophys. Expanded Abstracts, 696-699.

Bianchi, T. S., Pennock, J. R., and Twilley, R. R., 1999, Biogeochemistry of Gulf of Mexico estuaries: John Wiley \& Sons, Inc.

Ellis, R. G., 1998, Inversion of airborne electromagnetic data: Expl. Geophys., 29, 121-127.

Fletcher, R., 1987, Practical methods of optimization, 2nd ed.: John Wiley \& Sons, Inc.

Fountain, D., 1998, Airborne electromagnetic systems- 50 years of development: Expl. Geophys., 29, 1-11.

Frischknecht, F. C., 1967, Fields about an oscillating magnetic dipole over a two-layer earth and application to ground and airborne electromagnetic surveys: Colo. School of Mines Quart., 62, 1-326.

Huang, H., and Fraser, D. C., 1996, The differential parameter method for multifrequency airborne resistivity mapping: Geophysics, 61 , $100-109$.

Kovacs, A., Holladay, J. S., and Bergeron, C. J., Jr., 1995, The footprint/ altitude ratio for helicopter electromagnetic sounding of sea-ice thickness: Comparison of theoretical and field estimates: Geophysics, 60, 374-380.

Moré, J. J., 1978, The Levenberg-Marquardt algorithm: Implementation and theory: Lecture notes in mathematics, No. 630-Numerical analysis, Springer-Verlag Inc.

Mozley, E., Kooney, T., Byman, D., and Fraley, D., 1991, Kings Bay airborne electromagnetic survey: Naval Oceanographic and Atmospheric Research Laboratory, Advanced Survey and Sensor Branch, Report ID 019:352:91.

Nocedal, J., and Wright, S. J., 1999, Numerical optimization: SpringerVerlag Inc.

Pelletier, R. E., and Holladay, K. W., 1994, Mapping sediment and water properties in a shallow coastal environment with airborn electromagnetic profile data: Case study-The Cape Lookout, NC area: Marine Technology Soc. J., 28, 57-67.

Pelletier, R. E and Wu, S. T 1989, A preliminary evaluation of the airborne electromagnetic bathymetry system for characterization of coastal sediments and marsh soils: Ann. Conv., Am. Soc. for Photogrammetry and Remote Sensing/Am. Cong. on Surveying and Mapping, Technical Papers, 3, 366-375.

Press, W. H., Flannery, B. P., Teukolsky, S. A. and Vetterling, W. T. 1989, Numerical recipes: The art of scientific computing (Fortran version): Cambridge Univ. Press.

Rabalais, N. N., and Turner, R. E., Eds., 2001, Costal hypoxia: Consequences for living resources and ecosystems: Am. Geophys. Union.

Sengpiel, K. P. 1983, Resistivity depth mapping with airborne electromagnetic survey data: Geophysics, 48, 181-196.

Sommerfeld, A. N., 1909, The propagation of waves in wireless telegraphy: Ann. Phys., 28, 665-736.

Visual Numerics, Inc., 1994, IMSL F90 MP library version 3.0: IMSL Software.

Wait, J. R., 1951, The magnetic dipole over the horizontally stratified earth: Can. J. Phys., 29, 577-592.

1991, Complex image theory-Revisited: The Radioscientist, 2, 44-47.

Wiseman, W. J., Jr., and Garvine, R. W., 1995, Plumes and coastal currents near large river mouths: Estuaries, 18, 509-517.

Won, I. J., and Smits, K., 1987, Airborne electromagnetic measurements of electrical conductivities of seawater and bottom sediments over shallow ocean: Marine Geotech., 7, 1-14.

Xie, X., Macnae, J., and Reid, J., 1998, The limitations of 1-D AEM inversion for 2-D overburden structures: 68th Ann. Internat. Mtg., Soc. Expl. Geophys., Expanded Abstracts, 760-763. 